\title{
Lithium Ameliorates Nucleus Accumbens Phase-Signaling Dysfunction in a Genetic Mouse Model of Mania
}

\author{
Kafui Dzirasa, ${ }^{1,5}$ Laurent Coque, ${ }^{6}$ Michelle M. Sidor, ${ }^{6}$ Sunil Kumar, ${ }^{1}$ Elizabeth A. Dancy, ${ }^{6}$ Joseph S. Takahashi, ${ }^{7,8}$ \\ Colleen A. McClung, ${ }^{6}$ and Miguel A. L. Nicolelis ${ }^{2,3,4,5,9}$ \\ Departments of ${ }^{1}$ Psychiatry and Behavioral Sciences, ${ }^{2}$ Neurobiology, ${ }^{3}$ Psychology and Neuroscience, and ${ }^{4}$ Biomedical Engineering, and ${ }^{5}$ Center for \\ Neuroengineering, Duke University Medical Center, Durham, North Carolina 27710, Departments of ${ }^{6}$ Psychiatry and ${ }^{7}$ Neuroscience and ${ }^{8}$ Howard Hughes \\ Medical Institute, University of Texas Southwestern Medical Center, Dallas, Texas 75390-9111, and ${ }^{9}$ Edmond and Lily Safra International Institute of \\ Neuroscience of Natal, Natal, RN 59066-060, Brazil
}

Polymorphisms in circadian genes such as CLOCK convey risk for bipolar disorder. While studies have begun to elucidate the molecular mechanism whereby disruption of Clock alters cellular function within mesolimbic brain regions, little remains known about how these changes alter gross neural circuit function and generate mania-like behaviors in Clock- $\Delta 19$ mice. Here we show that the phasic entrainment of nucleus accumbens (NAC) low-gamma $(30-55 \mathrm{~Hz})$ oscillations to delta $(1-4 \mathrm{~Hz})$ oscillations is negatively correlated with the extent to which wild-type (WT) mice explore a novel environment. Clock- $\Delta 19$ mice, which display hyperactivity in the novel environment, exhibit profound deficits in low-gamma and NAC single-neuron phase coupling. We also demonstrate that NAC neurons in $C l o c k-\Delta 19$ mice display complex changes in dendritic morphology and reduced GluR1 expression compared to those observed in WT littermates. Chronic lithium treatment ameliorated several of these neurophysiological deficits and suppressed exploratory drive in the mutants. These results demonstrate that disruptions of Clock gene function are sufficient to promote alterations in NAC microcircuits, and raise the hypothesis that dysfunctional NAC phase signaling may contribute to the mania-like behavioral manifestations that result from diminished circadian gene function.

\section{Introduction}

Nearly all of the genes that control circadian rhythms are expressed in the mesolimbic pathways, and studies have demonstrated that these genes play an important role in regulating behaviors associated with mesolimbic circuit function (Abarca et al., 2002; McClung et al., 2005; Manev and Uz, 2006; Roybal et al., 2007; Lynch et al., 2008). For example, disruption of the circadian genes Period and Clock leads to changes in the reward value for drugs of abuse (Abarca et al., 2002; McClung et al., 2005; Spanagel et al., 2005). As such, it has been suggested that alterations in circadian gene function may play a role in mediating human neuropsychiatric illnesses. Bipolar disorder is a psychiatric illness that affects $1-3 \%$ of the U.S. population, and is characterized by manic and depressive symptoms (American Psychiatric Association, 2000). Polymorphisms in a number of circadian genes have been shown to convey risk for this illness, and individuals with bipolar disorder experience major disruptions in nearly all bio-

\footnotetext{
Received Aug. 16, 2010; revised Sept. 27, 2010; accepted 0ct. 4, 2010.

This work was supported by funding from United Negro College Fund/Merck and National Institute of Mental Health (NIMH) Grant P50MH060451-09S1 to K.D.; National Institute on Drug Abuse, NIMH, The Blue Gator Foundation, and the National Alliance for Research on Schizophrenia and Depression to C.A.M.; and National Institutes of Health (NIH) Grant R33NS049534, NIH Grant P50MH060451, and The Safra Foundation to M.A.L.N. We thank L. Oliveira, T. Jones, and G. Wood for miscellaneous support; M. G. Caron and H. Zhang for helpful comments on this manuscript; and S. Halkiotis for proofreading of this manuscript. We give special thanks to Freeman Hrabowski, Robert and Jane Meyerhoff, and the Meyerhoff Scholarship Program.

Correspondence should be addressed to Dr. Kafui Dzirasa, Department of Psychiatry and Behavioral Sciences, Duke University Medical Center, 333 Bryan Research Building, Durham, NC 27710. E-mail: dzira001@mc.duke.edu. DOI:10.1523/JNEUROSCI.4289-10.2010

Copyright $\odot 2010$ the authors $\quad$ 0270-6474/10/3016314-10\$15.00/0
}

logical rhythms (Benedetti et al., 2003; Nievergelt et al., 2006; McClung, 2007; Kripke et al., 2009; Soria et al., 2010).

Mice with an $N$-ethyl- $N$-nitrosourea (ENU)-induced point mutation in the circadian gene Clock (Clock- $\Delta 19$ mice) (Vitaterna et al., 1994; King et al., 1997) display behaviors that are very similar to human bipolar patients in the manic state. These behaviors include an increased exploratory drive in novel environments, a significant reduction in sleep, decreased anxiety-related behaviors, and an increase in cocaine preference (Naylor et al., 2000; Roybal et al., 2007). Many of these aberrant behaviors observed in Clock- $\Delta 19$ mice can be treated with lithium (Roybal et al., 2007), a medication commonly used to manage similar behavioral manifestation in human patients suffering from bipolar disorder (Grandjean and Aubry, 2009). While studies in Clock- $\Delta 19$ mice have begun to elucidate the molecular mechanism whereby disruptions in the Clock gene alter cellular function within mesolimbic brain regions (McClung et al., 2005), little is known about how the coalescence of these cellular changes alters gross mesolimbic circuit function and ultimately generates the behavioral manifestations observed in these animals. Moreover, the mechanism whereby lithium ameliorates the aberrant mania-like behaviors observed in these mice also remains obscure.

Here we set out to quantify mesolimbic circuit function in Clock- $\Delta 19$ mice by conducting simultaneous neurophysiological extracellular recordings across three mesolimbic brain areas [nucleus accumbens (NAC), prelimbic cortex (PrL-an anatomical subdivision of medial prefrontal cortex in rats), and ventral tegmental area (VTA)] as Clock- $\Delta 19$ mice and 
Table 1. Implanted coordinates

\begin{tabular}{llll}
\hline Area & AP $(\mathrm{mm})$ & $\mathrm{ML}(\mathrm{mm})$ & DV $(\mathrm{mm})$ \\
\hline NAC & +1.25 & +1.15 & -3.9 \\
PrL & +2.5 or +1.7 & \pm 0.25 & -0.75 or -1.8 \\
VTA & -3.2 & +0.3 & -4.25 \\
\hline
\end{tabular}

All coordinates are measured from bregma.

their wild-type (WT) littermate controls explored a novel environment.

\section{Materials and Methods}

Animal care and use. Clock- $\Delta 19$ mice were created by ENU mutagenesis and produce a dominant-negative CLOCK protein as previously described (King et al., 1997). Clock mutants and their WT littermate controls were bred from heterozygous $\left(\operatorname{Clock}^{\Delta 19} /+\right)$ breeding pairs on a $\mathrm{BALB} / \mathrm{cJ}$ and $\mathrm{C} 57 \mathrm{BL} / 6 \mathrm{~J}$ mixed strain background. Male Clock- $\Delta 19$ $\left(\right.$ Clock $^{\Delta 19} /$ Clock $\left.^{\Delta 19}\right)$ and WT $(+/+)$ littermate controls, 20-30 weeks old, were used for electrophysiological experiments presented in this study. Mice at Duke University were housed on a $12 \mathrm{~h}$ light/dark cycle, three to five per cage, and maintained in a humidity- and temperaturecontrolled room with water available ad libitum. Animals used in the dendritic morphology and protein expression studies were bred and housed at University of Texas (UT) Southwestern Medical Center under similar conditions. For electrophysiological studies, 10 Clock- $\Delta 19$ mice and $11 \mathrm{WT}$ littermate controls were separated into individual cages, and surgically implanted with recording electrodes. Experiments were initiated following a 2 week recovery. Experiments were conducted during the first $6 \mathrm{~h}$ of the light cycle, and electrophysiological recordings were conducted for $10 \mathrm{~min}$ as animals explored a $10.75 \mathrm{inch} \times 10.75$ inch open-field test environment (Med Associates, MED-OFA-MS). Each animal was subjected to only one recording session.

All studies were conducted with approved protocols from the Duke University and UT Southwestern Medical Center Institutional Animal Care and Use Committees and were in accordance with the National Institutes of Health guidelines for the care and use of laboratory animals.

Surgery. Clock- $\Delta 19$ mice and WT littermate controls were anesthetized with ketamine $(100 \mathrm{mg} / \mathrm{kg})$ and xylazine $(10 \mathrm{mg} / \mathrm{kg})$, placed in a stereotaxic device, and metal ground screws were secured to the cranium. A total of 32-48 tungsten microwires were arranged in bundle arrays of $6-16$ wires (each wire separated by at least $250 \mu \mathrm{m}$ ), and implanted to target NAC core (some individual microwires in the bundle ended up in NAC shell), PrL [seven of the WT and Clock- $\Delta 19$ mice were implanted with microwire arrays in the posterior portion of $\operatorname{PrL}(1.7 \mathrm{~mm}$ anterior to bregma), while the remaining animals (four WT and three Clock- $\Delta 19$ mice) were implanted in the anterior portion $(2.5 \mathrm{~mm}$ anterior to bregma)], and VTA. Implanted coordinates are given in Table 1.

Implanted electrodes were anchored to ground screws using dental acrylic.

Neuronal and LFP data acquisition. Neuronal activity was sorted online and recorded using the Multi-Neuron Acquisition Processor system (Plexon). At the end of the recording, cells were sorted again using an offline sorting algorithm (Plexon) to confirm the quality of the recorded cells. Local field potentials (LFPs) were preamplified $(500 \times)$, filtered $(0.7-170 \mathrm{~Hz})$, and digitized at $500 \mathrm{~Hz}$ using a Digital Acquisition card (National Instruments) and a Multi-Neuron Acquisition Processor (Plexon). All electrophysiological recordings were referenced to two ground screws. Notably, ground wires tested from the two screws were isoelectric, demonstrating that ground loops were not introduced by this design. Recording segments demonstrating LFP saturation resulting from movement artifacts were excluded from analysis $(<0.1 \%$ of the total recorded data). LFPs were recorded from every implanted tungsten electrode. It is important to note that LFP recordings were associated with significant phase offsets that varied across frequencies (Nelson et al., 2008). These phase offsets were corrected using the FPAlign function (Plexon). A $60 \mathrm{~Hz}$ bandstop filter was applied to LFPs used to estimate oscillatory power and cross-structural coherence.
Determination of LFP oscillatory power. A sliding window Fourier transform was applied to the LFP signal using Matlab (MathWorks), and the mean power across the recording periods of interest was determined. To quantify difference in LFP power between genotypes, we performed a two-way ANOVA of frequency $\times$ power followed by a one-way ANOVA of the mean LFP power within each frequency of interest. Results were subjected to a false discovery rate (FDR) correction at $\alpha=0.05 /(5$ frequencies) (Benjamini et al., 2001). Similar analysis was performed to determine the influence of speed on oscillatory power.

Determination of phase locking. LFPs were filtered using Butterworth bandpass filters designed to isolate LFP oscillations within the delta (1-4 $\mathrm{Hz}$ ), theta $(4-11 \mathrm{~Hz})$, beta $(15-25 \mathrm{~Hz})$, low-gamma $(30-55 \mathrm{~Hz})$, or high-gamma $(70-100 \mathrm{~Hz})$ frequency range. The instantaneous phase of the filtered LFP was then determined using the Hilbert transform (Siapas et al., 2005), and phase locking was detected using the Rayleigh test (Siapas et al., 2005; Jacobs et al., 2007) at $\alpha=0.05$. Phase-locking analysis was performed using exactly 400 events/cell to control for the effect of spike events on phase-locking results. Cells that fired $<400$ times during the $10 \mathrm{~min}$ recording $(<0.66 \mathrm{~Hz})$ were excluded from phase-locking analysis (15/120 NAC cells, 22/120 PrL cells, and 77/398 VTA cells). All neuronal phase-locking data in the text are presented in terms of population statistics, allowing us to maintain an $\alpha$ level of $\alpha=0.05$ despite the number of independent comparisons made. Statistically significant differences between genotypes were determined using a two-tailed $z$ test followed by an FDR correction (Benjamini et al., 2001) at a corrected $P$ value $<0.05$.

Determination of LFP cross-frequency phase coupling. To identify the phase/amplitude bands that displayed coupling, LFPs were filtered using Butterworth bandpass filters designed to isolate $0.5-19 \mathrm{~Hz}$ oscillations (in $1 \mathrm{~Hz}$ increments for phase analysis) and $15-100 \mathrm{~Hz}$ oscillations (in 5 $\mathrm{Hz}$ increments for amplitude analysis). The instantaneous amplitude and phase of the filtered LFPs were then determined using the Hilbert transform, and the modulation index was calculated using the MATLAB code provided by Canolty et al. (2006). Briefly, a continuous variable $z(t)$ is defined as a function of the instantaneous theta phase and instantaneous gamma amplitude such that $z(t)=A_{\mathrm{G}}(t) \times e_{\mathrm{TH}}^{i \phi(t)}$, where $A_{\mathrm{G}}$ is the instantaneous gamma oscillatory amplitude, and $e_{\mathrm{TH}}^{i \phi}$ is a function of the instantaneous theta oscillatory phase. A time lag is then introduced between the instantaneous amplitude and theta phase values such that $z_{\text {surr }}$ is parameterized by both time and the offset between the two variables, $z_{\text {surr }}=A_{\mathrm{HG}}(t+\tau) \times e_{\mathrm{TH}}^{i \phi(t)}$. The modulus of the first moment of $z(t)$, compared to the distribution of surrogate lengths, provides a measure of coupling strength. The normalized $z$-scored length, or modulation index, is then defined as $M_{\mathrm{NORM}}=\left(M_{\mathrm{RAW}}-\mu\right) / \sigma$, where $M_{\mathrm{RAW}}$ is the modulus of the first moment of $z(t), \mu$ is the mean of the surrogate lengths, and $\sigma$ is their standard deviation. Importantly, $M_{\text {NORM }}$ is a $Z$-score and can be used to determine the probability that a result would be due to chance.

After determining the optimal bands for phase-amplitude coupling, LFPs were filtered using Butterworth bandpass filters designed to isolate $1-4 \mathrm{~Hz}, 30-55 \mathrm{~Hz}$, and $70-100 \mathrm{~Hz}$ oscillations. The instantaneous amplitude and phase of these filtered LFPs were then determined using the Hilbert transform and the modulation index value was calculated for each LFP channel/mouse. Finally, the modulation index was calculated as the average modulation value observed across all of the LFP channels corresponding to a single brain area at a Bonferroni-corrected significance threshold of $\alpha=0.0001 /[12$ ( 3 brain areas $\times 2$ frequency bands $\times$ 2 genotypes)]. Comparisons across genotype were then made by using a Mann-Whitney $U$ test. A corrected $P$ value $<0.05$ was considered significant.

To determine the effect of speed on the entrainment of NAC lowgamma oscillations to delta oscillations, we calculated the modulation index for LFP data selected from periods when mice were moving at $<4$ $\mathrm{cm} / \mathrm{s}, 4-8 \mathrm{~cm} / \mathrm{s}$, and $>8 \mathrm{~cm} / \mathrm{s}$. To control for the length of LFP recordings used for calculation of the modulation index, we oversampled LFP data to obtain $10 \mathrm{~min}$ of LFP data for each speed. This resulted in an oversampling ranging from $\sim 33 \%$ for $<4 \mathrm{~cm} / \mathrm{s}$ data [animals spent $75 \%$ of their time in this speed range (see supplemental Fig. S1, available at www.jneurosci.org as supplemental material)] to $\sim 900 \%$ for $>8 \mathrm{~cm} / \mathrm{s}$ 
data (animals spent $\sim 10 \%$ of their time in this range). This approach skewed modulation index results in a manner that increased values obtained at high speeds. Notably, even with this bias, significant delta modulation was never observed across NAC, PrL, and VTA at medium (4-8 $\mathrm{cm} / \mathrm{s})$ or high $(>8 \mathrm{~cm} / \mathrm{s})$ speeds in WT or Clock- $\Delta 19$ mice.

Determination of lithium effects on mesolimbic activity in Clock- $\Delta 19$ mice. Following initial electrophysiological recordings, Clock- $\Delta 19$ mice were treated with lithium for $10 \mathrm{~d}$ as previously described (Roybal et al., 2007), and electrophysiological recording experiments were repeated. Statistical significance for within-genotype pairwise comparisons was determined using a two-tailed $z$ test. A corrected $P$ value $<0.05$ was considered significant.

Dendritic analysis of NAc neurons. Eight- to ten-week-old wild-type and homozygous Clock mutant littermates mice were group housed in a 12/12 h light/dark cycle, with ad libitum food and water. Lithium was administered through the drinking water for $10 \mathrm{~d}$ in the form of $\mathrm{LiCl}$ at $600 \mathrm{mg} / \mathrm{L}$. Mice were anesthetized by an injection of a mixture of xylazine and ketamine. Mice were then perfused for $5 \mathrm{~min}$ with a solution of $1 \times$ PBS to allow for exsanguination. Mouse brains were kept for 2 weeks in a fixative solution containing potassium chromate, potassium dichromate and mercuric chloride (FD Rapid GolgiStain Kit, FD NeuroTechnologies). After freezing the brains in isopentane, $150 \mu \mathrm{m}$ sections were obtained with a cryostat (Leica CM3050 S, Leica Microsystems). After development, sections were analyzed with Neurolucida software (MBF Bioscience). Neuron tracing and spine count were performed on medium spiny neurons of the striatum. The dendrite network analysis of traced neurons was performed using the Sholl method implemented with the NeuroExplorer software (MBF Bioscience): a series of concentric circles was overlaid on a projection of a neuron. The total dendrite length and number of nodes within the shells defined by each pair of consecutive rings was measured. The total number of dendrite intersections for each Sholl radius was also computed. Total differences across all Sholl circles in dendritic length, nodes, or intersections were compared using the Wilcoxon signed-rank test with a one-tailed $P ; \alpha<0.05$ was used as a threshold for significance.

Tissue collection and SDS-PAGE. Mice were killed with the Muromachi microwave fixation system to enhance preservation of the proteins' phosphorylation state. Nucleus Accumbens punches were then taken from fixed brain slices and immediately frozen. For protein extraction, tissue samples were homogenized by sonication on wet ice in a buffer containing $320 \mathrm{~mm}$ sucrose, $5 \mathrm{~mm}$ HEPES, phosphatase inhibitor cocktail I and II (Sigma), protease inhibitor (Sigma), 5\% SDS, and $50 \mathrm{~mm} \mathrm{NaF}$. Protein homogenate was spun at $12,000 \mathrm{RPM}$ for $10 \mathrm{~min}$ at $4^{\circ} \mathrm{C}$ and the supernatant carefully removed. DC assays (Bio-Rad) were performed to quantitate protein levels. Aliquots of sample were combined in Laemmli sample buffer (Bio-Rad) and 2-mercaptoethanol, and heated at $65^{\circ} \mathrm{C}$ for $20 \mathrm{~min}$. Samples were quickly spun, loaded (10 $\mu \mathrm{g}$ of total protein per lane), and electrophoresed on a precast 7.5\% Tris- $\mathrm{HCl}$ gel (Bio-Rad) at $100 \mathrm{~V}$ for $\sim 90 \mathrm{~min}$ in $1 \times$ TGS buffer (Bio-Rad). Proteins were transferred overnight at $4^{\circ} \mathrm{C}$ onto PVDF membranes at $35 \mathrm{~V}$ in $1 \times \mathrm{TG}$ buffer.

Western blots. Membranes were rewet briefly in a series of methanol, MilliQ water, and $1 \times$ PBS and then blocked in Odyssey Blocking Buffer (LI-COR Biosciences) for $1 \mathrm{~h}$ at room temperature (RT). Membranes were incubated overnight at RT with the following primary antibodies diluted in blocking buffer $+0.2 \%$ Tween 20: mouse anti-GAPDH (1: 20,000, Santa Cruz Biotechnology) and GluR1 (1:100, Santa Cruz Biotechnology); and rabbit anti-phospho GluR1 Ser-845 (1:1000, Abcam), GluR2 (1:400, Abcam), NR1 (1:1000, Cell Signaling Technology), NR2A (1:500, Abcam), and NR2B (1:2000; Cell Signaling Technology). Blots were washed in $1 \times$ PBS $+0.1 \%$ Tween 20 and incubated for $45 \mathrm{~min}$ at RT with infrared (IR)Dye 680-conjugated goat anti-rabbit (1:5000, LI-COR Biosciences) and IRDye 800-conjugated goat anti-mouse secondary (1:5000, LI-COR Biosciences) antibodies diluted in $0.2 \%$ Tween $20+0.02 \%$ SDS. Blots were washed in $1 \times$ PBS $+0.1 \%$ Tween 20 with a final wash in $1 \times$ PBS. Blots were scanned using the Odyssey Infrared Imaging System (LI-COR Biosciences) interfaced to a PC running Odyssey 2.1 software for quantification.

Protein bands were quantified using an integrated intensity and mean band background subtraction method. These values were then expressed as a ratio to the corresponding GAPDH integrated intensity to control for potential discrepancies in amount of protein loaded between samples.
For visualization purposes only, the contrast and brightness of Western blot images were enhanced using Adobe Photoshop 9.0 software. Settings for enhancement were applied across an entire given image to maintain relative differences in intensities between bands. Significant differences were determined by two-way ANOVA followed by post hoc tests.

Statistics. Behavioral, anatomical, and biochemical experiments, and spike sorting were conducted blind to genotype. Analysis, though not blind for the physiological experiments, was largely automated. All data are presented as mean \pm SEM.

\section{Results}

\section{Clock- $\Delta 19$ mice exhibit deficits in NAC low-gamma phase coupling}

Mice recovered very well and behaved normally after the surgical implantation with microelectrodes, allowing us to simultaneously record LFP and neuronal activity across three structures that contribute to mesolimbic circuits in awake, non-restrained conditions (Fig. 1A,B). Electrophysiological recordings were conducted as $11 \mathrm{WT}$ and 10 Clock- $\Delta 19$ explored a novel environment consisting of an open field. When we quantified mesolimbic LFP power in the two groups, our results indicated that WT and Clock- $\Delta 19$ mice displayed similar oscillatory power across all of the mesolimbic areas and frequencies examined [two-way ANOVA revealed insignificant genotype by frequency interactions $\left(F_{(204,4304)}=0.52,0.43\right.$, and 0.18 for NAC, PrL, and VTA oscillatory power, respectively; $P>0.05$ for all comparisons) (Fig. 1C)]. In addition to the amplitude component, the phase component of LFP oscillatory activity has also been shown to correlate with neural network function (Bragin et al., 1995; Siapas et al., 2005; Canolty et al., 2006; Sirota et al., 2008; Dzirasa et al., 2009; Sigurdsson et al., 2010). Thus, we set out to examine whether Clock- $\Delta 19$ mice displayed any alterations in mesolimbic LFP phase activity. Cross-frequency phase coupling (CFPC), a phenomenon in which the amplitude of high-frequency neural oscillatory activity is modulated by the phase of low-frequency neural oscillations (Fig. 2A), has been observed across mesolimbic brain structures such as hippocampus and prefrontal cortex (Bragin et al., 1995; Sirota et al., 2008; Dzirasa et al., 2009). Thus, we quantified mesolimbic CFPC in WT and Clock- $\Delta 19$ mice. We found that WT mice displayed phase coupling between lowgamma $(30-55 \mathrm{~Hz})$ and local delta $(1-4 \mathrm{~Hz})$ neural oscillations within NAC, and phase coupling between high-gamma (70-100 $\mathrm{Hz}$ ) oscillations and delta activity within NAC and PrL. No significant CFPC was observed within VTA in WT mice. Clock- $\Delta 19$ mice also displayed phase coupling between high-gamma (70$100 \mathrm{~Hz}$ ) oscillations and local delta activity within NAC and PrL $(P=0.23$ and 0.35 for comparisons of NAC and PrL high-gamma CFPC between genotypes, respectively); however, phase coupling between NAC low-gamma oscillatory activity and delta activity was disrupted in these mutants, and PrL low-gamma CFPC tended to be decreased $(P=0.01$ and 0.19 for comparisons of NAC and PrL low-gamma CFPC, respectively, between genotypes) (Fig. 2C). Additionally, VTA low- and high-gamma CFPC modulation values tended to be lower in Clock- $\Delta 19$ mice; however, these differences did not reach statistical significance $(P=$ 0.24 and $P=0.10$ for comparisons of VTA low- and high-gamma CFPC between genotypes, respectively), and the overall VTA modulation measured for both genotypes and frequency values were lower than the threshold for significant modulation. Since our results indicated that the dysfunctional NAC low-gamma CFPC observed in Clock- $\Delta 19$ mice represented a selective (i.e., brain area and frequency specific) and profound neurophysiological deficit, we investigated whether normal NAC low-gamma CFPC correlated with behaviors in WT mice. 


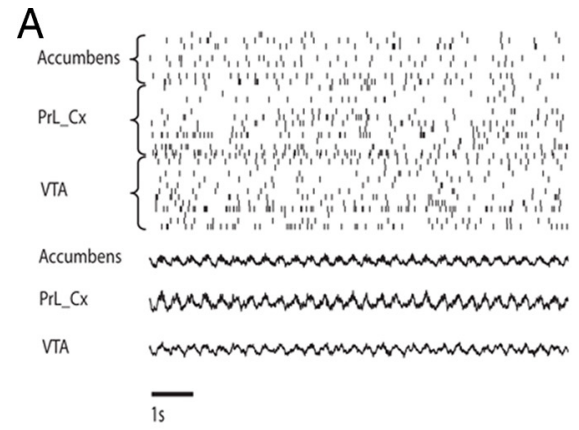

B
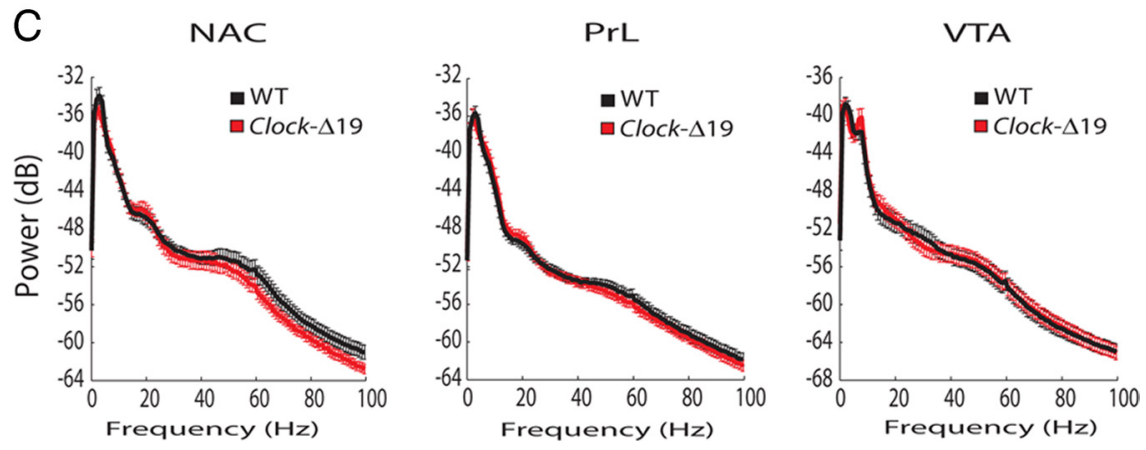

Figure 1. Multisite electrophysiological recordings in WT and Clock- $\Delta 19$ mice. $\boldsymbol{A}$, Raster plot of LFPs and 35 neurons simultaneously recorded from NAC, PrL, and VTA in an awake behaving animal. $\boldsymbol{B}$, Diagram of mesolimbic dopamine reward circuit (note that projections from NAC to VTA are not direct). C, LFP spectral power in WT and Clock- $\Delta 19$ mice during recording session.

nificant NAC low-gamma CFPC at any of the speeds of forward locomotion we examined (NAC low-gamma CFPC: $2.52 \pm$ $0.52,1.38 \pm 0.27$, and $1.04 \pm 0.28$ at $0-4$ $\mathrm{cm} / \mathrm{s}, 4-8 \mathrm{~cm} / \mathrm{s}$, and $>8 \mathrm{~cm} / \mathrm{s}$, respectively; Fig. 2E). Together, these results show that Clock- $\Delta 19$ mice fail to display the NAC low-gamma CFPC observed in WT mice during behaviorally immobile periods $(P=0.02$ for comparison of NAC low-gamma CFPC between genotypes at $<4 \mathrm{~cm} / \mathrm{s}$ ). When we investigated whether these deficits were due to alterations in NAC LFP oscillatory power at low speeds in Clock- $\Delta 19$ mice, a two-way ANOVA between WT and Clock- $\Delta 19$ mice revealed no significant genotype effect in NAC LFP power at speeds ranging from 0 to $4 \mathrm{~cm} / \mathrm{s}$ $\left(F_{(1,3894)}=2.04\right)$. Overall, since CFPC deficits were observed during periods when Clock- $\Delta 19$ mice were not engaged in forward locomotion, these results demonstrate that Clock- $\Delta 19$ mice display profound deficits in NAC low-gamma CFPC (compared to WT mice) that are not due to the increased behavioral profiles displayed by the mutants (see Fig. $4 D$ and supplemental Fig. S1, available

NAC low-gamma CFPC correlates with exploratory behaviors in WT mice

We found that NAC low-gamma CFPC was negatively correlated with the total distance each mouse traveled during the recording period in WT mice $[R=-0.61, P=0.047(R=-0.73, P=0.011$ for regression of logarithmic values) ]. Moreover, although NAC CFPC was disrupted during periods of forward locomotion (NAC low-gamma CFPC: $1.29 \pm 0.27$ and $1.05 \pm 0.22$ at $4-8$ $\mathrm{cm} / \mathrm{s}$ and $>8 \mathrm{~cm} / \mathrm{s}$, respectively; $P<0.01$ for both speeds compared to CFPC values observed at $<4 \mathrm{~cm} / \mathrm{s}$ ), the CFPC values observed during the 10 min recording period were directly correlated with CFPC values observed when analysis was restricted to periods when WT mice were not engaged in forward locomotion (i.e., $<4 \mathrm{~cm} / \mathrm{s} ; R=0.97, P<0.0001$ ). Finally, the CFPC values observed during periods when animals were not engaged in forward locomotion were also directly correlated with CFPC values observed during quiet waking periods while WT mice were in their home cage $(R=0.72, P=0.019)$. Thus, the differences in NAC low-gamma CFPC observed across WT mice were still present when animals were not actively engaged in forward locomotion, suggesting that the NAC low-gamma CFPC values seen across mice did not simply reflect their average speed during the recording period. Rather, NAC low-gamma CFPC correlated with the likelihood that animals would engage in forward locomotion. Incidentally, we also found that NAC high-gamma CFPC was disrupted during periods of forward locomotion in WT mice (NAC high-gamma CFPC: $2.37 \pm 0.56$ and $2.09 \pm 0.51$ at $4-8 \mathrm{~cm} / \mathrm{s}$ and $>8 \mathrm{~cm} / \mathrm{s}$, respectively; $P=0.13$ and 0.51 , respectively).

\section{Clock- $\Delta 19$ mice exhibit deficits in NAC low-gamma CFPC during immobile periods}

In Clock- $\Delta 19$ mice, NAC low-gamma CFPC was not correlated with the total distance traveled during the 10 min recording period $(P=0.72)$. Moreover, Clock- $\Delta 19$ mice failed to exhibit sig- at www.jneurosci.org as supplemental material). Notably, though NAC low-gamma CFPC tended to be lower in Clock$\Delta 19$ mice compared to WT mice during periods of quiet waking while animals were in their home cage, these differences did not reach statistical significance (NAC low-gamma CFPC: $6.90 \pm 1.85$ and $4.79 \pm 1.06$ for WT and Clock- $\Delta 19$ mice, respectively; $P=0.35$ ).

\section{Clock- $\Delta 19$ mice exhibit neuronal entrainment deficits in NAC}

To investigate whether these alterations in LFP phase coupling were consistent with changes in neuronal phase activity in Clock$\Delta 19$ mice, we chronically recorded the extracellular activity of 638 neurons, distributed as follows: 120 neurons in the nucleus accumbens, 120 neurons in the prelimbic cortex, and 398 neurons in the VTA from WT mice and Clock- $\Delta 19$ mice (Table 2). Phase locking, a phenomenon in which neuronal firing is phase synchronized to LFP oscillatory activity (Fig. $3 B$ ), has been observed across several mesolimbic brain structures (Jones and Wilson, 2005; Siapas et al., 2005; Jacobs et al., 2007). Thus, we quantified neuronal phase locking to delta oscillations (i.e., $1-4 \mathrm{~Hz}$ ) occurring within each of the mesolimbic brain areas examined (supplemental Fig. S2, available at www.jneurosci.org as supplemental material). This frequency band was chosen for our analysis because our results had previously indicated that mesolimbic gamma neural oscillatory activity phase coupled to lowfrequency oscillations occurring in this range.

Detailed analysis of our neuronal data revealed that a significant proportion of NAC $(52 \%, n=50), \operatorname{PrL}(30 \%, n=56)$, and VTA $(42 \%, n=155)$ neurons phase locked to locally recorded delta oscillatory activity in WT mice (Fig. 3D). Moreover, we found that NAC, PrL, and VTA neurons tended to optimally phase lock to the rising phase of locally recorded delta oscillations. Clock- $\Delta 19$ mice also displayed a significant proportion of NAC $(30 \%, n=53), \operatorname{PrL}(43 \%, n=42)$, and VTA $(50 \%, n=166)$ neurons that phase locked to locally recorded (within the same 
brain area) delta oscillations, and phase locked neurons tended to optimally couple to the rising phase of locally recorded delta oscillations (as they had in WT mice). However, the proportion of NACneurons that phase locked to local oscillatory activity was significantly diminished in Clock- $\Delta 19$ mice (Fig. 3E). Notably, since we controlled for the number of spike events used for phase-locking analysis (phase-locking analysis is highly dependent on the number of spike events used for quantification), the deficits in NAC-neuron delta phase locking observed in Clock- $\Delta 19$ mice were not simply due to differences in neuronal firing rates (supplemental Fig. S3, available at www. jneurosci.org as supplemental material). Together, our results strongly suggest that Clock- $\Delta 19$ mice display deficits in delta oscillation NAC phase signaling (CFPC and neuronal phase locking) that do not simply result from changes in LFP oscillatory power or changes in neuronal firing rates.

\section{Lithium ameliorated CFPC and neuronal phase-locking deficits in Clock- $\Delta 19$ mice}

Previous studies have demonstrated that chronic treatment with lithium attenuates many of the mania-like behaviors displayed by Clock- $\Delta 19$ mice (Roybal et al., 2007). Thus, we also investigated the effect of chronic lithium treatment on the delta oscillation phase-signaling deficits we had identified in Clock- $\Delta 19$ mice. Following our initial baseline recordings, seven Clock- $\Delta 19$ mice were treated with lithium for $10 \mathrm{~d}$, and electrophysiological recordings were repeated as mice explored the open field. Chronic lithium treatment significantly increased NAC low-gamma CFPC in Clock- $\Delta 19$ mice [NAC lowgamma $\mathrm{CFPC}=6.36 \pm 0.74$ in lithiumtreated Clock- $\Delta 19$ mice during periods of immobility (i.e., $<4 \mathrm{~cm} / \mathrm{s}$ ); $P=0.002$ compared with untreated Clock- $\Delta 19$ mice], and ameliorated the NAC neuronal phaselocking deficits (53\% of NAC neurons entrained to delta oscillations, $n=32 ; P<0.05)$ and behavioral hyperactivity observed in untreated Clock- $\Delta 19$ mice (Fig. 4). Notably, treatment with lithium did not alter high-gamma CFPC across any of the brain areas examined in Clock- $\Delta 19$ mice and WT mice, nor NAClow-gamma CFPC or NAC phase locking ( $n=24$ neurons) in WT mice ( $P>0.05$ for all comparisons).

\section{Clock- $\Delta 19$ mice exhibit diminished AMPA receptor subunit expression in NAC}

Overall, our results suggested that the delta oscillation phasesignaling deficits displayed by Clock- $\Delta 19$ mice were primarily limited to NAC. Thus, we investigated whether these phasesignaling deficits were associated with biochemical and morphological changes in NAC microcircuits. Computational models have indicated that NAC phase signaling is highly dependent on they were moving $<4 \mathrm{~cm} / \mathrm{s}$.
B

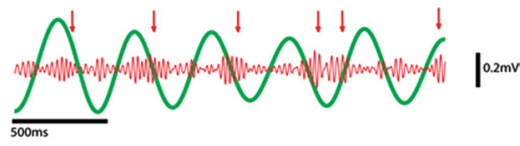

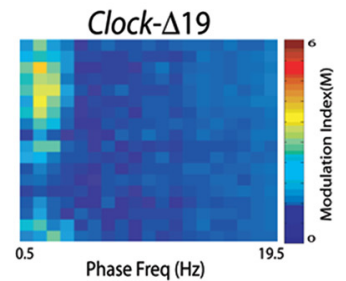

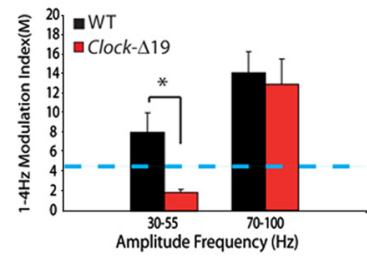

Amplitude Frequency $(\mathrm{Hz})$

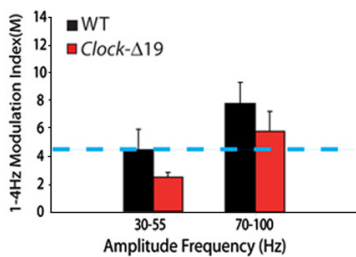

Phase Freq $(\mathrm{Hz})$
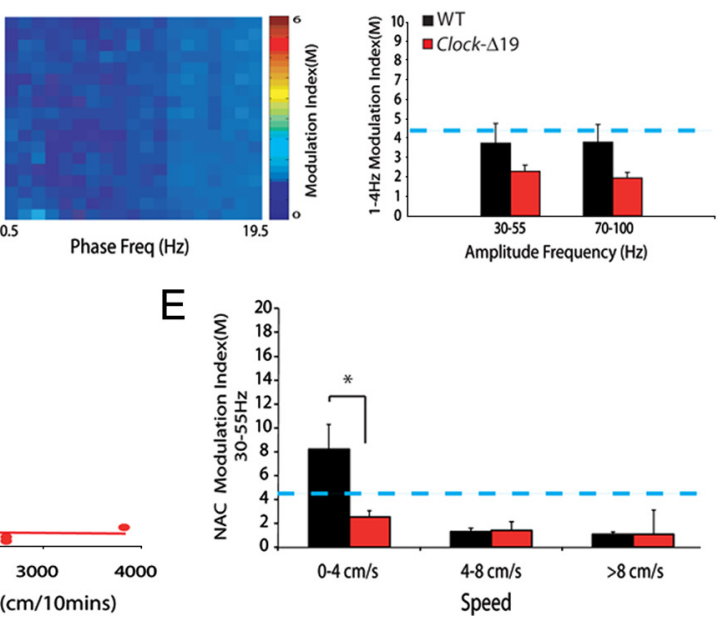

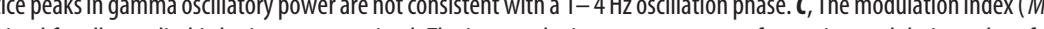
amplitude oscillations occurring between 15 and $100 \mathrm{~Hz}$ and phase oscillations occurring between $0.5 \mathrm{and} 19.5 \mathrm{~Hz}$. Clock- $\Delta 19$ mice displayed diminished coupling between the phase of 1-4 Hz oscillations and the amplitude of low-gamma $(30-55 \mathrm{~Hz})$ oscillations. The blue line indicates threshold for significant phase coupling; ${ }^{*}$ Corrected $P<0.05$. D, Modulation index of NAC low-gamma oscillations versus total distance traveled. $\boldsymbol{E}$, Clock- $\Delta 19$ mice failed to display CFPC during periods when

Table 2. Total number of neurons isolated per mouse per brain area

\begin{tabular}{llll}
\hline & NAC & PrL & VTA \\
\hline WT mice & 5.1 & 6.7 & 16.8 \\
Clock- $\Delta 19$ mice & 6.4 & 4.6 & 21.4 \\
\hline
\end{tabular}

NAC glutamatergic signaling. For example, one model suggested that decreases in the NMDA/AMPA ratios may be sufficient to disrupt the entrainment of NAC neurons to afferent oscillatory activity (Wolf et al., 2005). Since our findings indicated that the entrainment of NAC neuronal and low-gamma LFP activity to delta oscillations was diminished in Clock- $\Delta 19$, we wanted to investigate whether Clock- $\Delta 19$ mice exhibited changes in the expression of glutamate receptor subunits in NAC. Using Western blot analysis, we found that levels of the AMPA receptor subunit, 

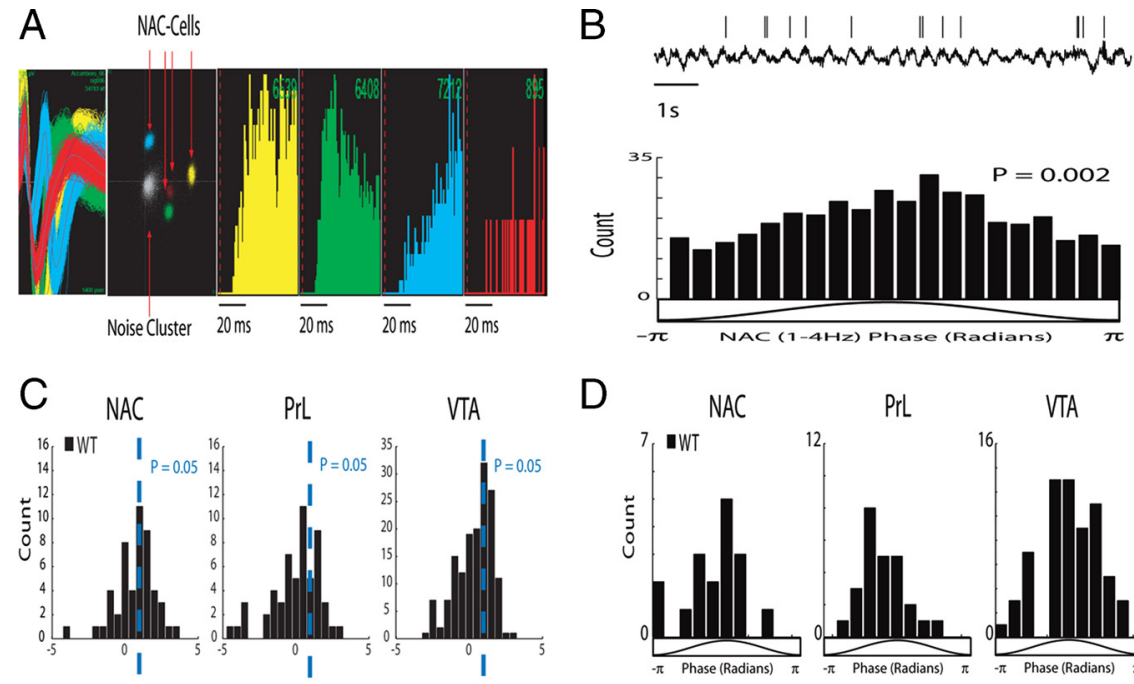

D
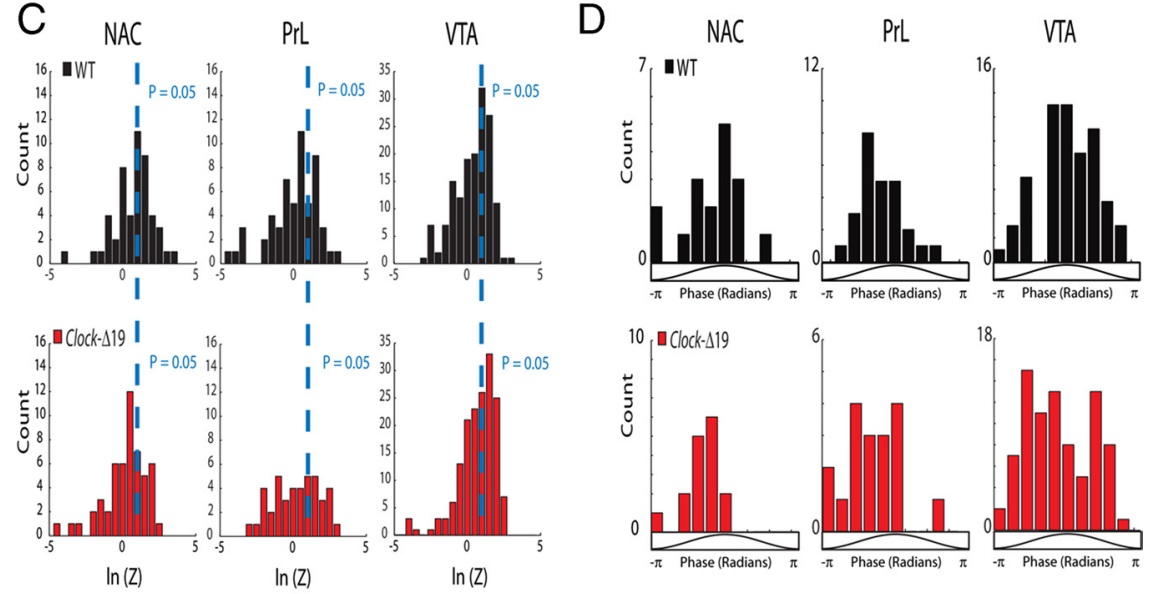

E

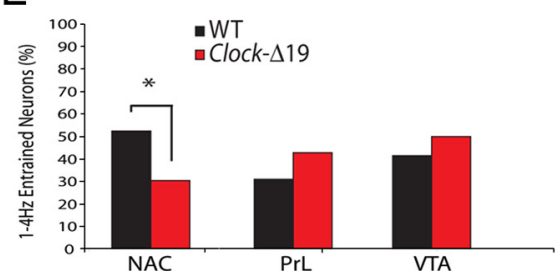

Figure 3. Neuronal phase locking across mesolimbic brain areas in WT and Clock- $\Delta 19$ mice. $A$, Example of four neurons isolated from NAC. From left to right: depiction of the four extracellularly recorded waveforms of the unit ( $x$-axis $1400 \mu$ s; $y$-axis $188 \mu \mathrm{V}$ ); projection of the clusters correspondent to the units and the noise based on analysis of the first two principal components of the waveforms recorded ( $x$-axis, PC1; $y$-axis, PC2); and interspike interval histogram. $B$, Example of single-neuron phase locking, and the phase distribution of NAC neuron shown above. The activity of the depicted neuron was phase locked to the $1-4 \mathrm{~Hz}$ oscillation peak. C, Raleigh statistic for all NAC, PrL, and VTA neurons in WT and Clock- $\Delta 19$ mice. D, NAC, PrL, and VTA neurons in WT and Clock- $\Delta 19$ mice optimally phase locked to the rising phase of delta oscillations. $E$, Clock- $\Delta 19$ mice displayed a significantly lower proportion of NAC neurons that were phase locked to delta oscillatory activity than did WT mice. Two-tailed paired $z$ test with FDR correction, ${ }^{*}$ Corrected $P<0.05$.

GluR1, and p-GluR1 were significantly reduced in the NAC of Clock- $\Delta 19$ mice compared to WT littermates (Fig. $5 A, B$ ). When we calculated the ratio of P-GluR1/GluR1, we found no differences across genotype or with lithium treatment (data not shown), suggesting that Clock- $\Delta 19$ mice display a reduction in total GluR1 levels, but not in the degree of GluR1 phosphorylation. Notably, chronic lithium treatment did not increase GluR1 or p-GluR1 levels in Clock- $\Delta 19$ mice, but did lead to a decrease in GluR1 and p-GluR1 levels in wild-type animals (Fig. 5A,B). We also measured levels of the GluR2 subunit of the AMPA receptor and found no differences in expression across genotypes or treatments (Fig. 5C). Similarly, when we measured levels of the NMDA receptor subunits NR1, NR2A, and NR2B, we found no differences in expression (Fig. 5D-F).

\section{Clock- $\Delta 19$ mice exhibit altered NAC medium spiny neuron morphology}

Several studies have also associated structural plasticity of NAC medium spiny neurons with complex behavioral measures such as sen-

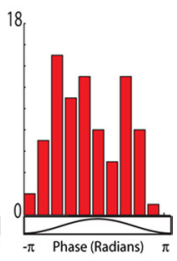

sitization to psychostimulants and depression-related behavior following maternal separation (Li et al., 2004; Monroy et al., 2010). Thus, we stained brain sections containing the NAC of both Clock- $\Delta 19$ and WT mice with the Golgi method to examine changes in dendritic length, complexity, and spine density (Fig. 6A). Using Neurolucida software to count the number of dendritic spines per segment, we found no difference in spine density between Clock- $\Delta 19$ mice and their WT littermates (Fig. 6B). Furthermore, treatment with chronic lithium did not alter the spine density of either the Clock- $\Delta 19$ or WT animals. Next, to determine whether there were any differences in dendritic length or complexity in NAC neurons, we performed Sholl analysis, which uses an overlay of concentric rings around the soma of each individual neuron (Sholl, 1956). We found that the NAC neurons in the Clock- $\Delta 19$ animals generally had greater dendritic length, particularly at $80 \mu \mathrm{m}$ and beyond from the center of the Sholl circle (Fig. 6C). In addition, the dendrites of these neurons intersected the Sholl circles more often, indicating that their pattern was more complex than the dendrites in WT animals (Fig. 6D). Lithium treatment significantly reversed the number of intersections in the Clock- $\Delta 19$ mice, and there was a trend toward a reversal in total dendritic length. Lithium treatment had the opposite effect on dendritic length and intersections in the WT animals, leading to a general increase in length and a greater number of intersections. Lithium treatment in WT animals also resulted in a significant increase in dendritic nodes; however, there was no difference between the Clock- $\Delta 19$ with or without lithium and WT animals in this measure (Fig. 6E). Together, these results indicated that the medium spiny neurons in the NAC of Clock- $\Delta 19$ mice had longer and more complex dendrites than those of WT mice. Furthermore, lithium treatment in Clock- $\Delta 19$ mice reversed some of these structural differences, making the dendrites more like those of WT animals. On the other hand, lithium treatment in WT mice had the opposite effect, in that it made the dendrites of these animals longer and more complex.

\section{Discussion}

Bipolar disorder is a heterogeneous neuropsychiatric disorder characterized by manic and depressive symptoms. As with other neuropsychiatric illnesses, bipolar disorder undoubtedly results from complex changes across widely distributed brain circuits (Akil et al., 2010). As such, many independent genetic changes are likely to yield the structural and biochemical changes underlying this disorder, and many different structural and biochemical changes are likely to be sufficient to alter circuits critical to normal behavioral function in bipolar patients. Here we show that a disruption of the Clock gene is sufficient to induce biochemical, morphological, and neurophysiological changes in NAC micro- 
circuits. While all patients with bipolar disorder do not exhibit alterations in circadian genes, our findings do provide a circuit-based link between the genetic changes observed in at least a specific subset of bipolar patients and the behavioral manifestations associated with the disorder. Notably, the circuit-based manifestations that we report in Clock- $\Delta 19$ mice may reflect a common neurophysiological pathway that is disrupted by many of the genetic alterations associated with bipolar disorder.

The nucleus accumbens has been implicated in mediating behaviors associated with reward, addiction, and mood (Nestler, 2004; Nestler and Carlezon, 2006), and Clock- $\Delta 19$ mice have been shown to display a mania-like syndrome characterized by increased novelty-induced behavioral hyperactivity, a significant reduction in sleep, decreased anxiety-related behaviors, and an increase in several rewardrelated behaviors (McClung et al., 2005; Naylor et al., 2000; Roybal et al., 2007). Here we show that NAC low-gamma CFPC correlates with exploratory behaviors in WT mice. We also show that Clock$\Delta 19$ mice exhibit deficits in NAC lowgamma CFPC during periods when their behavioral profiles are similar to those observed in WT animals, and we demonstrate that Clock- $\Delta 19$ mice exhibit deficits in NAC neuronal phase locking. Importantly, these phase-signaling deficits are not accompanied by changes in LFP oscillatory power or changes in NAC firing rates. Finally, we show that all of the neurophysiological deficits observed in Clock-

$\Delta 19$ mice can be ameliorated by lithium treatment (an agent commonly used to manage symptoms in bipolar patients). Together, our findings suggest that NAC phase-signaling dysfunction may contribute to the neurophysiological mechanisms underlying the mania-like behavioral manifestations that result from disrupted circadian gene function.

Neural phase signaling has gained attention as a putative coding mechanism through which the brain binds the activity of neurons across mesolimbic brain structures to generate percepts, feelings, and behaviors. For example, studies have suggested that the synchronization of hippocampal and amygdalar neural oscillatory activity may play a role in fear conditioning (Seidenbecher et al., 2003), and the phase synchronization of rhinal and hippocampal oscillations is observed during memory formation (Fell et al., 2001). Moreover, multiple studies in rodents have suggested that the phase locking of hippocampal and prefrontal cortical single neurons to hippocampal neural oscillatory activity may play a role in coordinating spatial-cognitive processes (Jones and Wilson, 2005; Siapas et al., 2005). More recently, changes in neural oscillatory synchrony across mesolimbic circuits have been associated with the generation of abnormal repetitive behaviors in mice acutely depleted of norepinephrine (Dzirasa et al., 2010), and it has been reported that alterations in hippocampal and prefrontal cortical cross-frequency phase coupling may facilitate spatial cognitive dysfunction (Dzirasa et al., 2009). Together, these studies suggest that phase signaling may play an important role in coordinating mesolimbic network function, and raise the hypothesis that alterations in neural oscillatory phase signaling may mediate several neuropsychiatric disorders (Uhlhaas and Singer, 2006; Uhlhaas et al., 2008). Importantly, recent studies have suggested that alterations in neural oscillatory phase timing may mediate the behavioral manifestations observed across other brain disorders, such as Parkinson's disease and schizophrenia, as well (Fuentes et al., 2009; Sigurdsson et al., 2010).

NAC low-gamma CFPC was negatively correlated with the overall behavioral profile of WT mice exploring the novel environment. Since CFPC values observed across WT mice were positively correlated with CFPC values quantified while animals were not engaged in forward locomotion, and while animals were in their home cage, our findings suggest that the differences in NAC low-gamma CFPC observed across WT mice do not simply reflect their overall behavior profile. Rather, our findings suggest that NAC low-gamma CFPC negatively correlates with the extent to which WT mice are likely to explore a novel environment (exploratory drive). Notably, NAC low-gamma activity has been shown to reflect both the initiation of movement and reward delivery (van der Meer and Redish, 2009). On the other hand, our findings indicate that Clock- $\Delta 19$ mice display a selective (brain area and frequency specific) disruption of NAC low-gamma CFPC. Since Clock- $\Delta 19$ mice display hyperactivity in novel envi- 
A
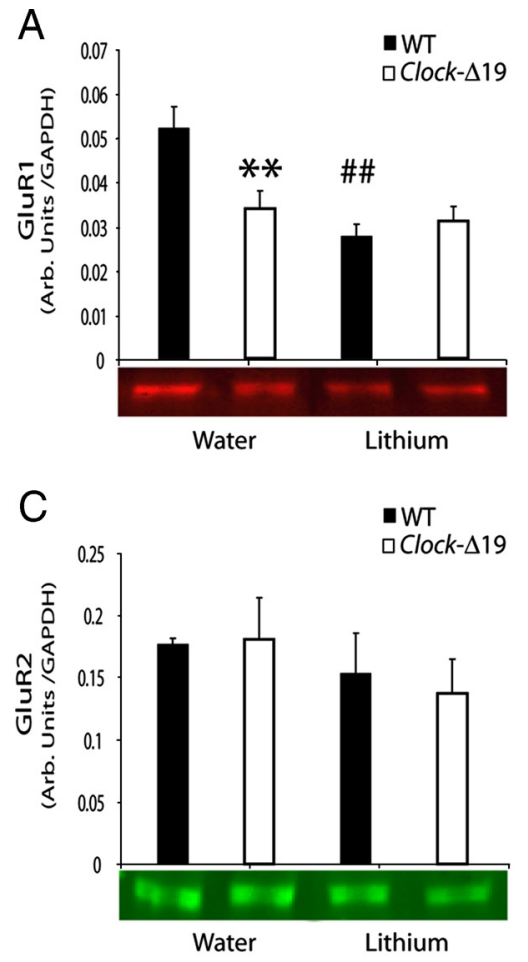

E

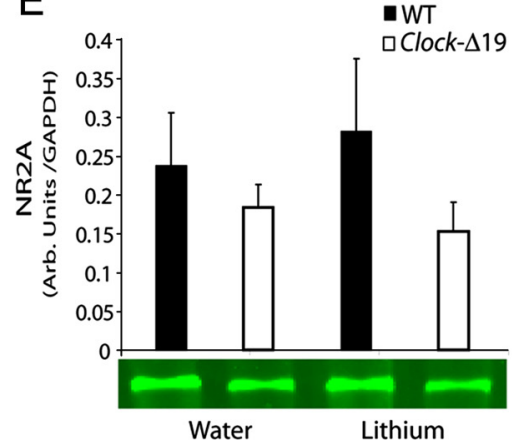

B
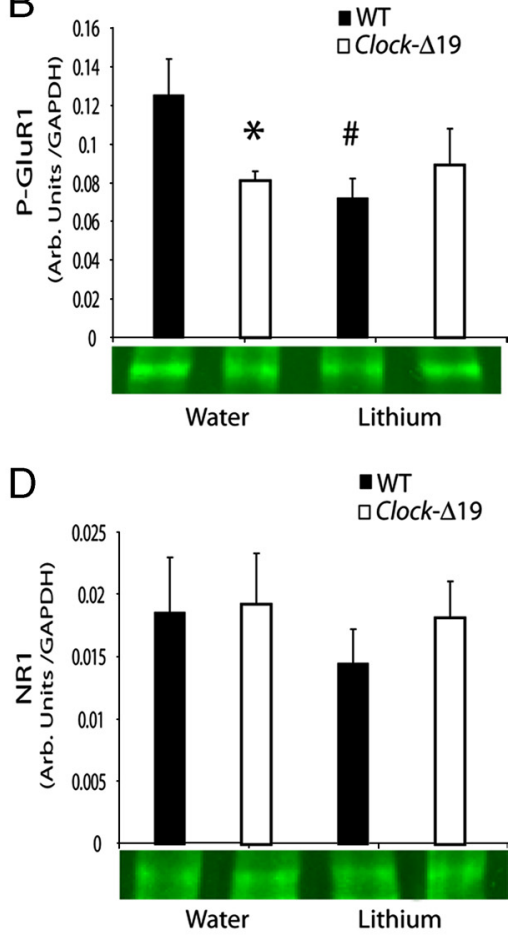

F

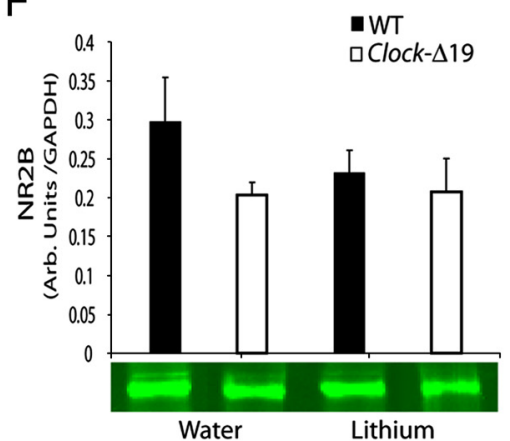

Figure 5. Analysis of NAC glutamatergic function in WT and Clock- $\Delta 19$ mice. Levels of AMPA and NMDA receptor subunits were quantified by Western blotting in Clock $\Delta 19$ mutants and WT controls treated with vehicle or lithium. Representative blots are shown below the corresponding graph. There was a significant decrease in GluR1 $(\boldsymbol{A})$ and phospho-ser845 GluR1 (B) in Clock $\Delta 19$ mutant mice relative to WT. Lithium decreased protein levels of GluR1 and P-GluR1 in WT mice only. No changes in GluR2 (C), NR1 $(\boldsymbol{D})$, NR2A $(\boldsymbol{E})$, or NR2B $(\boldsymbol{F})$ levels were observed. All values are expressed as ratios relative to levels of GAPDH. $n=5-6 /$ group; comparisons made by two-way ANOVA followed by post hoc analysis, ${ }^{*} p<0.05,{ }^{* *} p<0.01$, for across genotype comparisons ${ }^{\#} p<0.05,{ }^{\# \#} p<0.01$, for lithium treatment comparisons.

ronments and alterations in reward processing (McClung et al., 2005; Roybal et al., 2007), the altered NAC low-gamma CFPC observed in Clock- $\Delta 19$ mice may correspond with deficits in NAC microcircuits involved in regulating their exploratory drive.

Our results indicate that compared to WT mice, the NAC medium spiny neurons of Clock- $\Delta 19$ mice display longer and more complex dendrites and a reduced expression of the AMPA receptor (AMPAR) subunit GluR1 and p-GluR1. Notably, decreased phosphorylation of GluR1 at Ser845 is associated with a reduced synaptic expression of GluR1-containing receptors and decreased AMPA transmission (Song and Huganir, 2002; Mangiavacchi and Wolf, 2004). Since neuronal phase locking is thought to occur via complex interactions between individual neurons that belong to local or faraway populations (Siapas et al., 2005), alterations in NAC dendritic morphology and glutamatergic receptor gene expression may contribute to disruptions of phase signaling. Supporting this hypothesis, computational models of NAC medium spiny neuron function suggest that alterations in NMDA and AMPA expression may be sufficient to disrupt the phasic entrainment of medium spiny neurons to afferent inputs (Wolf et al., 2005). While these models were designed to test the entrainment of medium spiny neurons to afferent inputs in the theta range, it is plausible that these results hold true for the entrainment of NAC neurons to oscillatory input in the delta range as well. NAC delta oscillations are highly coherent with PrL delta oscillations during periods when animals are not engaged in forward locomotion (supplemental Fig. S3, available at www.jneurosci. org as supplemental material). Moreover, our findings indicate that NAC neuronal activity and low-gamma oscillatory activity entrains to delta oscillations during these behavioral periods as well. Since prefrontal cortex burst firing has been shown to reliably induce up states in NAC neurons in rats (Gruber et al., 2009), the changes in NAC dendritic morphology and AMPAR subunit expression observed in Clock- $\Delta 19$ mice may diminish prefrontal cortical control over NAC activity. These neurophysiological changes may then lead to deficits in cortically driven inhibitory control, ultimately facilitating the increased novelty- and reward-seeking behaviors displayed by Clock- $\Delta 19$ mice.

Our findings also demonstrate that treatment with lithium, in addition to reducing the mania-like symptoms of Clock- $\Delta 19$ mice, tends to reverse many of the changes in dendritic morphology observed in Clock- $\Delta 19$ mice and increases the entrainment of NAC neurons and low-gamma oscillations to delta oscillations. Since treatment with lithium did not increase GluR1 or p-GluR1 expression in Clock- $\Delta 19$ mice, nor did it fully restore NAC phase signaling in Clock- $\Delta 19$ mice to levels observed in WT littermates (though lithium did increase NAC phase signaling overall), our findings suggest that treatment with lithium likely increases NAC phase signaling in Clock- $\Delta 19$ mice via a GluR1-independent mechanism. On the other hand, treatment with lithium decreased NAC GluR1 and p-GluR1 expression, and altered the dendritic morphology of NAC neurons in WT mice. Notably, lithium did not alter NAC CFPC or the phase locking of NAC to local oscillatory activity in WT mice, suggesting that reductions in NAC GluR1 and p-GluR1 expression are likely not sufficient (in and of themselves) to induce all of the neurophysiological changes observed in Clock- $\Delta 19$ mice. This is supported by our data, which demonstrate that Clock- $\Delta 19$ mice display normal NAC low-gamma CFPC during periods of quiet waking in their home cage.

One potential mechanism underlying the disruption of NAC low-gamma CFPC and phase signaling observed in Clock- $\Delta 19$ mice may involve a selective alteration of physiological activity in 
NAC neurons expressing $\mathrm{D}_{2}$-dopamine receptors $\left(\mathrm{D}_{2}\right.$-DRs). $\mathrm{D}_{2}$-DRs modulate GSK-3 $\beta$ phosphorylation via an Aktmediated signaling pathway (Beaulieu et al., 2004), and this pathway has been shown to be a major target of lithium (Beaulieu et al., 2004; Gould and Manji, 2005). Thus, the morphological, biochemical, and electrophysiological changes observed in the NAC of Clock- $\Delta 19$ mice may be due to a persistent overactivation of NAC $\mathrm{D}_{2}$-DRmediated GSK-3 $\beta$ signaling. Another mechanism underlying the phase-signaling deficits observed in Clock- $\Delta 19$ mice may involve changes in VTA feedback control due to alterations in $\mathrm{D}_{2}$ autoreceptor signaling. Incidentally, studies have demonstrated that Clock- $\Delta 19$ mice display increased bursting of dopaminergic neurons in VTA (McClung et al., 2005), and VTA dopaminergic cell bursting has been shown to promote mesolimbic dopamine release (Floresco et al., 2003). Moreover, selective restoration of Clock function in the VTA of Clock- $\Delta 19$ mice attenuates several of the behavioral manifestations observed in these animals (Roybal et al., 2007).

The present findings raise the hypothesis that the diminished phase locking observed in Clock- $\Delta 19$ mice may occur via a mechanism whereby disruption of the Clock gene leads to increased VTA cell bursting, which in turn promotes increased NAC dopamine release. This increased dopamine release then fosters changes in NAC microcircuits that diminish the overall weight of afferent glutamatergic inputs from prefrontal cortex. When coupled with changes in mesolimbic activity that normally follow novelty exposure, these microcircuit disruptions ultimately diminish the ability of NAC neurons to entrain to afferent input in the delta frequency range, leading to the phase-signaling deficits observed in Clock- $\Delta 19$ mice.

Together, our findings suggest that disruptions of Clock gene function lead to diminished NAC phase signaling, ultimately fostering mania-like behavioral dysfunction. Notably, the multidisciplinary findings presented in this manuscript are largely correlational across various layers of analysis. Thus, future studies will be critical to establish a causal link between the biochemical, morphological, neurophysiological, and behavioral alterations exhibited by Clock- $\Delta 19$ mice. Moreover, additional studies will be necessary to clarify whether the alterations in NAC neurophysiological function and dysfunctional behaviors described here lie upstream or downstream or remain independent of the circadian rhythm disruptions that follow diminished Clock gene function. Nevertheless, since the neurophysiological and behavioral changes that follow circadian gene disruption correspond with altered NAC LFP oscillatory

A
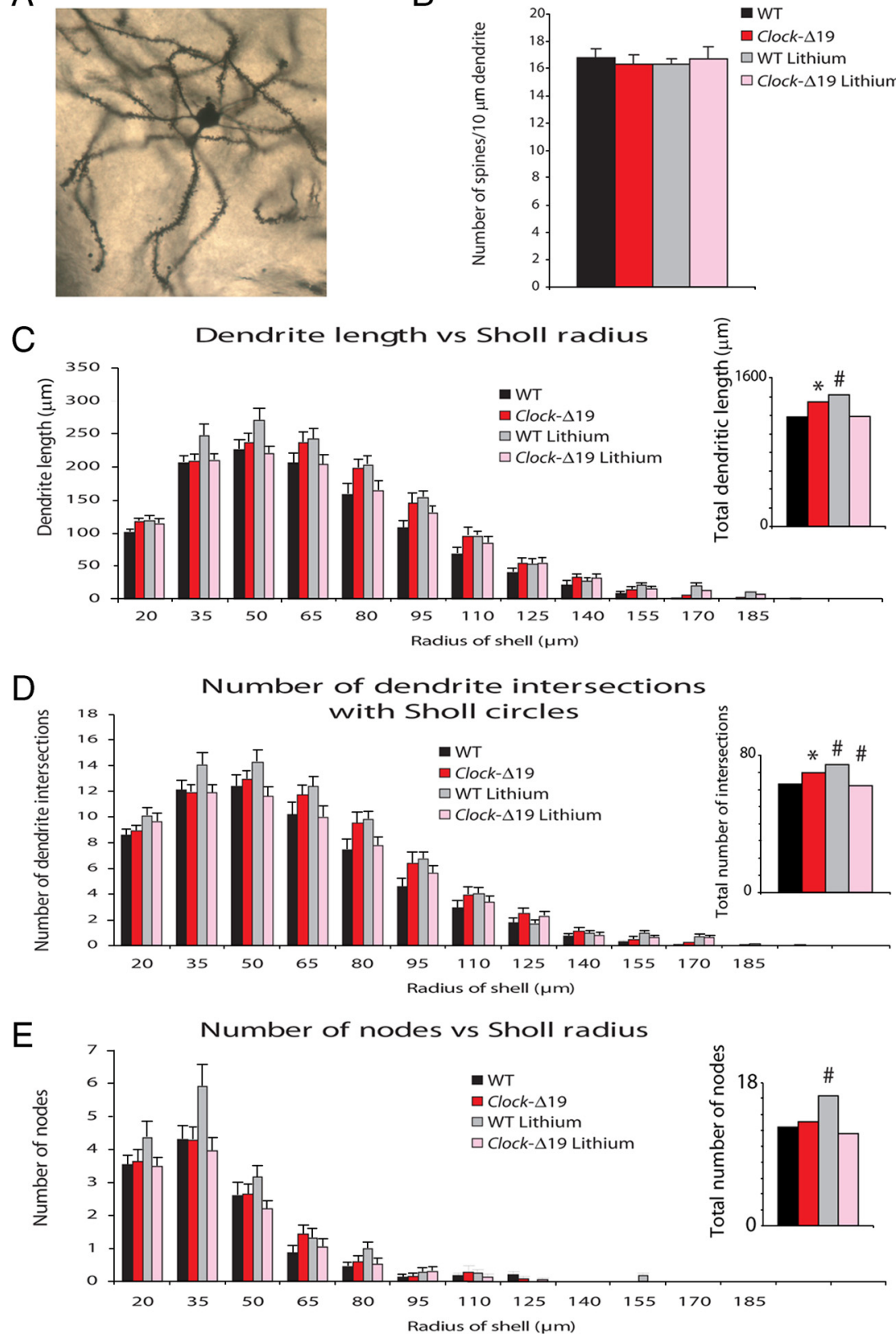

Figure 6. Analysis of the structural plasticity of NAC neurons in WT and Clock- $\Delta 19$ mice. Brains from Clock- $\Delta 19$ and WT animals with or without $10 \mathrm{~d}$ of lithium treatment $(600 \mathrm{mg} / \mathrm{L})$ were subjected to Golgi staining and then sliced into $150 \mu \mathrm{m}$ sections. Twenty-five to twenty-nine cells from the NAC were analyzed and averaged from five mice per group. $A$, Example of a Golgi-stained medium spiny neuron from NAC. $\boldsymbol{B}$, Dendritic spine density was measured. There were no differences in spine density between groups. $C$, Dendritic length across Sholl circles was measured. Clock- $\Delta 19$ mice have an increase in overall dendritic length across all Sholl radii compared to WT mice $(P<0.01)$. Lithium treatment tended to reduce overall dendritic length in the Clock- $\Delta 19$ mice, though this trend did not reach statistical significant $(P=0.095)$. Lithium treatment increased the length of dendrites in WT mice $(P<0.01)$. $\boldsymbol{D}$, The number of dendritic intersections of Sholl circles was calculated. Dendrites from Clock- $\Delta 19$ mice intersect Sholl circles more often than those of WT mice $(P<0.01)$. Lithium treatment significantly decreases these intersections in Clock- $\Delta 19$ mice $(P<0.05)$. Lithium treatment increases the number of dendritic intersections of Sholl circles in WT mice $(P<0.01)$. $E$, The number of dendritic nodes was calculated across Sholl circles. No significant differences were found between Clock- $\Delta 19$ and WT mice; however, lithium treatment increased the number of nodes in WT animals $(P<0.05)$. Insets for $\boldsymbol{C}-\boldsymbol{E}$ show totals measured across all lengths; ${ }^{*} P<0.05$ for across genotype comparison, ${ }^{\sharp} P<0.05$ for within genotype comparison of lithium effect.

phase signaling, our findings highlight a novel electrophysiological biomarker of mania-like behaviors that can potentially be used to directly diagnose or detect vulnerability to bipolar disorder in humans using emerging noninvasive techniques such as magnetoencephalography. 


\section{References}

Abarca C, Albrecht U, Spanagel R (2002) Cocaine sensitization and reward are under the influence of circadian genes and rhythm. Proc Natl Acad Sci U S A 99:9026-9030.

Akil H, Brenner S, Kandel E, Kendler KS, King MC, Scolnick E, Watson JD, Zoghbi HY (2010) Medicine. The future of psychiatric research: genomes and neural circuits. Science 327:1580-1581.

American Psychiatric Association (2000) Diagnostic and statistical manual of mental disorders DSM-IV-TR. Washington, DC: American Psychiatric Association.

Beaulieu JM, Sotnikova TD, Yao WD, Kockeritz L, Woodgett JR, Gainetdinov RR, Caron MG (2004) Lithium antagonizes dopamine-dependent behaviors mediated by an AKT/glycogen synthase kinase 3 signaling cascade. Proc Natl Acad Sci U S A 101:5099-5104.

Benedetti F, Serretti A, Colombo C, Barbini B, Lorenzi C, Campori E, Smeraldi E (2003) Influence of CLOCK gene polymorphism on circadian mood fluctuation and illness recurrence in bipolar depression. Am J Med Genet B Neuropsychiatr Genet 123B:23-26.

Benjamini Y, Drai D, Elmer G, Kafkafi N, Golani I (2001) Controlling the false discovery rate in behavior genetics research. Behav Brain Res 125:279-284.

Bragin A, Jandó G, Nádasdy Z, Hetke J, Wise K, Buzsáki G (1995) Gamma $(40-100 \mathrm{~Hz})$ oscillation in the hippocampus of the behaving rat. J Neurosci 15:47-60.

Canolty RT, Edwards E, Dalal SS, Soltani M, Nagarajan SS, Kirsch HE, Berger MS, Barbaro NM, Knight RT (2006) High gamma power is phaselocked to theta oscillations in human neocortex. Science 313:1626-1628.

Dzirasa K, Ramsey AJ, Takahashi DY, Stapleton J, Potes JM, Williams JK, Gainetdinov RR, Sameshima K, Caron MG, Nicolelis MA (2009) Hyperdopaminergia and NMDA receptor hypofunction disrupt neural phase signaling. J Neurosci 29:8215-8224.

Dzirasa K, Phillips HW, Sotnikova TD, Salahpour A, Kumar S, Gainetdinov RR, Caron MG, Nicolelis MA (2010) Noradrenergic control of corticostriato-thalamic and mesolimbic cross-structural synchrony. J Neurosci 30:6387-6397.

Fell J, Klaver P, Lehnertz K, Grunwald T, Schaller C, Elger CE, Fernández G (2001) Human memory formation is accompanied by rhinal-hippocampal coupling and decoupling. Nat Neurosci 4:1259-1264.

Floresco SB, West AR, Ash B, Moore H, Grace AA (2003) Afferent modulation of dopamine neuron firing differentially regulates tonic and phasic dopamine transmission. Nat Neurosci 6:968-973.

Fuentes R, Petersson P, Siesser WB, Caron MG, Nicolelis MA (2009) Spinal cord stimulation restores locomotion in animal models of Parkinson's disease. Science 323:1578-1582.

Gould TD, Manji HK (2005) Glycogen synthase kinase-3: a putative molecular target for lithium mimetic drugs. Neuropsychopharmacology 30:1223-1237.

Grandjean EM, Aubry JM (2009) Lithium: updated human knowledge using an evidence-based approach: part I: clinical efficacy in bipolar disorder. CNS Drugs 23:225-240.

Gruber AJ, Hussain RJ, O'Donnell P (2009) The nucleus accumbens: a switchboard for goal-directed behaviors. PLoS One 4:e5062.

Jacobs J, Kahana MJ, Ekstrom AD, Fried I (2007) Brain oscillations control timing of single-neuron activity in humans. J Neurosci 27:3839-3844.

Jones MW, Wilson MA (2005) Theta rhythms coordinate hippocampalprefrontal interactions in a spatial memory task. PLoS Biol 3:e402.

King DP, Zhao Y, Sangoram AM, Wilsbacher LD, Tanaka M, Antoch MP, Steeves TD, Vitaterna MH, Kornhauser JM, Lowrey PL, Turek FW, Takahashi JS (1997) Positional cloning of the mouse circadian clock gene. Cell 89:641-653.

Kripke DF, Nievergelt CM, Joo E, Shekhtman T, Kelsoe JR (2009) Circadian polymorphisms associated with affective disorders. J Circadian Rhythms 7:2.

Li Y, Acerbo MJ, Robinson TE (2004) The induction of behavioural sensitization is associated with cocaine-induced structural plasticity in the core (but not shell) of the nucleus accumbens. Eur J Neurosci 20:1647-1654.

Lynch WJ, Girgenti MJ, Breslin FJ, Newton SS, Taylor JR (2008) Gene profiling the response to repeated cocaine self-administration in dorsal striatum: a focus on circadian genes. Brain Res 1213:166-177.

Manev H, Uz T (2006) Clock genes: influencing and being influenced by psychoactive drugs. Trends Pharmacol Sci 27:186-189.

Mangiavacchi S, Wolf ME (2004) Stimulation of N-methyl-D-aspartate receptors, AMPA receptors or metabotropic glutamate receptors leads to rapid internalization of AMPA receptors in cultured nucleus accumbens neurons. Eur J Neurosci 20:649-657.

McClung CA (2007) Circadian genes, rhythms and the biology of mood disorders. Pharmacol Ther 114:222-232.

McClung CA, Sidiropoulou K, Vitaterna M, Takahashi JS, White FJ, Cooper DC, Nestler EJ (2005) Regulation of dopaminergic transmission and cocaine reward by the Clock gene. Proc Natl Acad Sci U S A 102:9377-9381.

Monroy E, Hernández-Torres E, Flores G (2010) Maternal separation disrupts dendritic morphology of neurons in prefrontal cortex, hippocampus, and nucleus accumbens in male rat offspring. J Chem Neuroanat 40:93-101.

Naylor E, Bergmann BM, Krauski K, Zee PC, Takahashi JS, Vitaterna MH, Turek FW (2000) The circadian clock mutation alters sleep homeostasis in the mouse. J Neurosci 20:8138-8143.

Nelson MJ, Pouget P, Nilsen EA, Patten CD, Schall JD (2008) Review of signal distortion through metal microelectrode recording circuits and filters. J Neurosci Methods 169:141-157.

Nestler EJ (2004) Molecular mechanisms of drug addiction. Neuropharmacology 47 [Suppl 1]:24-32.

Nestler EJ, Carlezon WA Jr (2006) The mesolimbic dopamine reward circuit in depression. Biol Psychiatry 59:1151-1159.

Nievergelt CM, Kripke DF, Barrett TB, Burg E, Remick RA, Sadovnick AD, McElroy SL, Keck PE Jr, Schork NJ, Kelsoe JR (2006) Suggestive evidence for association of the circadian genes PERIOD3 and ARNTL with bipolar disorder. Am J Med Genet B Neuropsychiatr Genet 141B:234-241.

Roybal K, Theobold D, Graham A, DiNieri JA, Russo SJ, Krishnan V, Chakravarty S, Peevey J, Oehrlein N, Birnbaum S, Vitaterna MH, Orsulak P, Takahashi JS, Nestler EJ, Carlezon WA Jr, McClung CA (2007) Mania-like behavior induced by disruption of CLOCK. Proc Natl Acad Sci U S A 104:6406-6411.

Seidenbecher T, Laxmi TR, Stork O, Pape HC (2003) Amygdalar and hippocampal theta rhythm synchronization during fear memory retrieval. Science 301:846-850.

Sholl DA (1956) The organization of the cerebral cortex. London: Methuen. Siapas AG, Lubenov EV, Wilson MA (2005) Prefrontal phase locking to hippocampal theta oscillations. Neuron 46:141-151.

Sigurdsson T, Stark KL, Karayiorgou M, Gogos JA, Gordon JA (2010) Impaired hippocampal-prefrontal synchrony in a genetic mouse model of schizophrenia. Nature 464:763-767.

Sirota A, Montgomery S, Fujisawa S, Isomura Y, Zugaro M, Buzsáki G (2008) Entrainment of neocortical neurons and gamma oscillations by the hippocampal theta rhythm. Neuron 60:683-697.

Song I, Huganir RL (2002) Regulation of AMPA receptors during synaptic plasticity. Trends Neurosci 25:578-588.

Soria V, Martínez-Amorós E, Escaramís G, Valero J, Pérez-Egea R, García C, Gutiérrez-Zotes A, Puigdemont D, Bayés M, Crespo JM, Martorell L, Vilella E, Labad A, Vallejo J, Pérez V, Menchón JM, Estivill X, Gratacòs M, Urretavizcaya M (2010) Differential association of circadian genes with mood disorders: CRY1 and NPAS2 are associated with unipolar major depression and CLOCK and VIP with bipolar disorder. Neuropsychopharmacology 35:1279-1289.

Spanagel R, Pendyala G, Abarca C, Zghoul T, Sanchis-Segura C, Magnone MC, Lascorz J, Depner M, Holzberg D, Soyka M, Schreiber S, Matsuda F, Lathrop M, Schumann G, Albrecht U (2005) The clock gene Per2 influences the glutamatergic system and modulates alcohol consumption. Nat Med 11:35-42.

Uhlhaas PJ, Singer W (2006) Neural synchrony in brain disorders: relevance for cognitive dysfunctions and pathophysiology. Neuron 52:155-168.

Uhlhaas PJ, Haenschel C, Nikolić D, Singer W (2008) The role of oscillations and synchrony in cortical networks and their putative relevance for the pathophysiology of schizophrenia. Schizophr Bull 34:927-943.

van der Meer MA, Redish AD (2009) Low and high gamma oscillations in rat ventral striatum have distinct relationships to behavior, reward, and spiking activity on a learned spatial decision task. Front Integr Neurosci 3:9.

Vitaterna MH, King DP, Chang AM, Kornhauser JM, Lowrey PL, McDonald JD, Dove WF, Pinto LH, Turek FW, Takahashi JS (1994) Mutagenesis and mapping of a mouse gene, Clock, essential for circadian behavior. Science 264:719-725.

Wolf JA, Moyer JT, Lazarewicz MT, Contreras D, Benoit-Marand M, O’Donnell P, Finkel LH (2005) NMDA/AMPA ratio impacts state transitions and entrainment to oscillations in a computational model of the nucleus accumbens medium spiny projection neuron. J Neurosci 25:9080-9095. 